\title{
O crepúsculo da função pública: distopia ou realidade? ${ }^{1}$
}

\author{
The twilight of the civil service: dystopia or reality?
}

\section{Selma Venco ${ }^{2}$ \\ Flávio Sousa ${ }^{3}$}

\section{Resumo}

O artigo visa debater as alterações nas formas de contratação no setor público, tomando como objeto de análise os professores da educação básica (exceto Educação de Jovens e Adultos e Educação profissional) nas escolas sob a responsabilidade dos estados da Federação e Distrito Federal. A pesquisa, de caráter documental, analisa a função pública composta por trabalhadoras voltados ao interesse geral da população, os quais são responsáveis por concretizar os direitos à população. A despeito de tal importância, observa-se: forte adesão ao gerencialismo por parte dos governos estaduais, aqui constatada pela crescente admissão de docentes sem concurso público e, portanto, fonte de precariedade nas relações de trabalho e gerador de um processo de precarização das condições de vida.

Palavras-clave: função pública; trabalho docente; precariedade; nova gestão pública.

\footnotetext{
${ }_{1}^{1}$ Pesquisa financiada pela Fundação de Amparo à Pesquisa do Estado de São Paulo (FAPESP), Processo no 2019/01552-3.

2 Docente da Faculdade de Educação da Universidade Estadual de Campinas (Unicamp), Departamento de Políticas, Administração e Sistemas Educacionais; Grupo de Estudos e Pesquisas em Política Educacional (GREPPE). Email: selma.venco@gmail.com

${ }^{3}$ Doutorando em Estado, Políticas Públicas e Educação da Faculdade de Educação da Universidade Estadual de Campinas (Unicamp); Grupo de Estudos e Pesquisas em Política Educacional (GREPPE). Email: saintflavio35@gmail.com
} 


\begin{abstract}
The article discuss the forms of contracting in the public sector, taking as object of analysis the teachers of basic education (except Youth and Adult Education and Professional Education) in schools under the responsibility of the states of the Federation and the Federal District.The documentary research analyzes the public function composed of workers turned to the general interest of the population, who are responsible for realizing the rights to the population. Notwithstanding such importance, it can be observed: strong adherence to managerialism on the part of state governments, because is growing the admission of teachers without public recruitment and, therefore, a source of precariousness in labor relations and a generator of a process of precariousness conditions of life.
\end{abstract}

Keywords: public function; teaching work; precariousness; new public management

\title{
1. Introdução
}

A construção e a difusão da noção de um Estado oneroso e incapaz de enfrentar os altos custos provenientes do Estado do Bem-Estar-Social - mesmo não tendo sido implementado no Brasil - e os desafios de uma sociedade globalizada, foram amplamente veiculadas no Brasil desde o primeiro governo eleito democraticamente, após vinte e um anos de ditadura civil-militar (1964-1985), e consolidada no governo Fernando Henrique Cardoso (1995-2008), cujas ações constituíram o arcabouço legal imperioso à consecução de tal opção política.

Alentado pela onda toyotista de flexibilização das relações, via contratos de trabalho por tempo determinado, terceirização e redução de acesso aos direitos vinculados ao trabalho, o governo federal adota medidas semelhantes concernentes ao emprego no setor público.

A matriz política prevalente nos anos 1990, aderente à lógica do setor empresarial, prega a transição do Estado burocrático para o gerencial, posto que uma administração pública moderna necessariamente deveria abandonar a rigidez 
burocrática e estimular a participação das empresas privadas nas ações públicas (Bresser-Pereira, 1998).

É nesse contexto que o presente artigo visa debater as alterações nas formas de contratação no setor público, tomando como objeto de análise os professores da educação básica (exceto Educação de Jovens e Adultos e Educação profissional) nas escolas sob a responsabilidade dos estados da Federação. A hipótese aqui considerada apoia-se na constatação de que as formas de afastamento do Estado são múltiplas e, muitas vezes, podem ser acobertadas por processos inevidentes aos olhos da população; associa-se a essa dimensão a existência de nítida intencionalidade em promover, por diversas vias, a redução exponencial do emprego público, posto que se privilegia a racionalidade econômica a qual se dá em detrimento da qualidade na oferta da educação pública.

A problematização construída sustenta-se em pesquisa documental cuja abrangência remete à análise dos dados estatísticos originários do Ministério da Educação, por meio do Censo Escolar de 2011 - ano em que se inicia a coleta de dados acerca das formas de contratação dos docentes da educação básica em todo o país - a 2018, data da última publicação do levantamento. Cabe esclarecer que as escolas respondem ao questionário, de maneira a assinalar a quantidade de professores concursados, temporários, contratados via Consolidação das Leis do Trabalho $(C L T)^{4}$ e terceirizados. Tendo em vista os ínfimos registros nas duas últimas categorias, optou-se por organizar os dados entre efetivos (concursados) e não efetivos, a fim de dar destaque às formas - aqui consideradas - atípicas de contratação de docentes da educação básica pelos governos estaduais e Distrito Federal.

O artigo organiza-se em três partes e considerações finais. Inicia-se apresentando a formação do Estado no Brasil e as articulações para o surgimento e alterações referentes às funções dos agentes públicos; em seguida, debate-se o sentido social da função pública e as especificidades do trabalho voltado ao interesse geral da população; e, por fim, a partir dessa base conceitual são

\footnotetext{
${ }^{4}$ Brasil (1943). Decreto-Lei $n$. 5.452, de $1^{\circ}$ de maio, aplicado aos contratos de trabalho firmados nas empresas privadas no Brasil.
} 
apresentados os dados referentes às relações de trabalho praticadas junto aos docentes das escolas estaduais em todo o Brasil e as características daqueles que são afetados por contratos de trabalho vulneráveis.

\section{As relações de poder na constituição do Estado brasileiro}

Congruente à formulação tecida por Engels (1984) considera-se, aqui no presente artigo, ser a constituição do Estado fruto de uma dada sociedade cindida em classes, com prevalência das garantias de acumulação e poder de uma sobre a outra.

Assim, a recuperação da formação do Estado no Brasil remete à constatação que as relações de poder foram alicerçadas no País no bojo da invasão portuguesa em 1500, cuja colonização de exploração, optante do escravagismo, retardou processos de independência política e econômica. Resulta desse processo a formalização do Estado somente em 1824, sob a égide da dominação patriarcal (Weber, 1999) fincada pela família real portuguesa que se instala em terras brasileiras.

Nesse contexto a ocupação de cargos administrativos respondia a uma sociedade altamente hierarquizada, pavimentando sua história calcada nos "privilégios hereditários" (Holanda, 1969, p. 35). Os "empregados públicos" recebem menção na Constituição de 1824, no artigo 179, prevendo, especialmente, a responsabilização desses por eventuais excessos praticados, quando do exercício da função pública.

Uma nova Carta Magna é promulgada em 1891, dois anos após a proclamação da República, com avanços no delineamento do Estado. Nela são criados: o federalismo e os três poderes; o Estado é declarado laico e se institui o voto aos homens livres e alfabetizados. Para Carvalho (1997) a República cria uma instância política em substituição aos antigos presidentes de Província, como tentativa de superação do patrimonialismo rumo ao Estado burocrático, cujas características demandariam a constituição de um funcionalismo público.

Nos primórdios do século XX ○ Brasil apresenta tímido processo de industrialização concentrado no setor têxtil e será mais diversificada nos primeiros 
anos da década de 1930, aspecto que exarou do Estado participação diferenciada na regulação necessária para o avanço da produção, particularmente no que tange à tomada de medidas econômicas de proteção e de incentivo à indústria.

Este cenário repercutiu diretamente na estruturação mais efetiva do funcionalismo público, foco de atenção na Constituição de 1934. Nela, são estabelecidas as normas para acesso aos cargos públicos e outros direitos vinculados ao trabalho, com ênfase na responsabilização decorrente de negligência ou abuso de poder. Holanda (1969) aponta os obstáculos a serem enfrentados pelos detentores de cargos públicos, dada a tenuidade que cliva interesses públicos dos privados.

Para o funcionário 'patrimonial', a própria gestão política apresenta- se como assunto de seu interesse particular; as funções, os empregos e os benefícios que deles aufere, relacionam-se a direitos pessoais do funcionário e não a interesses objetivos, como sucede no verdadeiro Estado burocrático, em que prevalece a especialização das funções e o esforço para se assegurarem garantias jurídicas aos cidadãos (p. 105).

Pondera-se que a instabilidade política é marca indelével na história do Brasil. Um Golpe de Estado em 1937, cuja defesa era a proteção dos ataques comunistas ao país e, de acordo com tal perspectiva, a Constituição deveria ser reelaborada com vistas a atender os princípios ideológicos dos que tomavam o poder naquele momento histórico e resulta em uma versão de nítida inspiração fascista. Passados oito anos do golpe a democracia é restaurada e nova Carta é proclamada, intencionando eliminar os traços ditatoriais presentes na anterior. Relativo ao funcionalismo público houve ascenso à estabilidade no cargo público aos ocupantes por cinco anos ou mais sem terem sido, no entanto, concursados. Essa possibilidade foi suprimida 30 anos após, com a instauração da ditadura civil-militar (1964-1985) que no art. 99, § 10 indica: "Ninguém pode ser efetivado ou adquirir estabilidade, como funcionário, se não prestar concurso público".

Em 1985 a democracia é restabelecida e, a despeito do país ter um presidente eleito indiretamente, houve eleições diretas em 1986 para deputados e a Assembleia Nacional Constituinte aprova nova Constituição em 1988. Elogiada 
internacionalmente e conhecida como "Constituição Cidadã" dados os avanços no reconhecimento de uma série de direitos, estes são até a atualidade de difícil efetivação.

A respeito da administração pública, a Carta no art. 37 reafirma a condição exclusiva de ingresso no setor público, via aprovação em concurso público. Não obstante confere, pela primeira vez, exceção ao estabelecer contratos atípicos no serviço público. No mesmo artigo, Inciso IX, considera que: "a lei estabelecerá os casos de contratação por tempo determinado para atender a necessidade temporária de excepcional interesse público" [grifos nossos].

As alterações aparentemente sutis na escrita da lei remetem a indagações acerca da provisoriedade dos contratos no setor público. Banderia de Mello (2010, p. 255) estabelece distinção entre cargo e emprego público. Para ele:

cargos são as mais simples e indivisíveis unidades de competência a serem expressadas por um agente, previstas em número certo, com denominação própria, retribuídas por pessoas jurídicas de Direito Público (...). Os servidores titulares de cargos públicos submetem-se a um regime especificamente concebido para reger esta categoria de agentes. Tal regime é estatutário ou institucional; logo, de índole não-contratual (p.256, [grifos dos nossos])

Enquanto empregos públicos:

são núcleos de encargos de trabalho permanentes a serem preenchidos por agentes contratados para desempenhá-los, sob relação trabalhista (...). Sujeitam-se a uma disciplina jurídica que, embora sofra inevitáveis influências advindas da natureza governamental da contratante, basicamente, é a que se aplica aos contratos trabalhistas em geral; portanto, a prevista na Consolidação das Leis do Trabalho (p. 256, [grifos nossos]).

Assim sendo, considera-se imperativo o debate referente ao preenchimento e ao exercício da função pública na viabilização dos direitos à população. 


\section{O sentido social da função pública}

A problematização aqui apresentada sobre a função pública distancia-se de qualquer proposição teórica de cunho funcionalista e concentra-se na formulação tecida por Pors e Aschieri (2015) que a concebem como o responsável pela execução da política pública, a qual, por princípio é promotora da igualdade e garante a efetividade do direito aos cidadãos. Para esses autores o trabalho dos funcionários públicos concretiza o interesse geral da população, pois não atende às demandas do capital e aos benefícios particulares.

A contratação dos agentes públicos via concurso público ${ }^{5}$, no caso brasileiro, permitiu romper com a herança patrimonialista, cuja constituição do Estado sustentava-se na indistinção entre as esferas pública e privada. Assim, uma seleção pública permite, teoricamente, a independência dos agentes públicos em defesa da política social. E, por essa razão, devem ter garantida a estabilidade no emprego, não por privilégio, mas para dar continuidade aos serviços à população, conforme as alterações nos cargos máximos e intermediários do poder público. Deste modo, os direitos inerentes ao cargo deveriam assegurar o devido distanciamento dos interesses particulares, colocando-se constantemente em favor da coletividade.

Além desse aspecto, aqui considerado de alta legitimidade, evoca-se outro, com base em Robert Castel (1998), que ressalta o papel social do Estado - condição sine qua non para o incremento da "interdependência social" - viabilizado pelos agentes públicos e que impede a "dissociação social". Essa se constitui na formulação central em favor da seleção pública, distinta da praticada no setor privado, posto serem os agentes públicos responsáveis por conferir a ininterrupção do acesso ao direito à população.

Pors e Aschieri (2015) dialogam com a perspectiva conceitual de Castel (1998) e sintetizam que o Estado se equipara a um "amortecedor social" e

\footnotetext{
${ }^{5}$ Concurso público é definido pela Lei n. 8.666/93, que institui as normas para licitações e contratos da Administração Pública, em seu artigo 22, como sendo: a modalidade de licitação entre quaisquer interessados para escolha de trabalho técnico, científico ou artístico, mediante a instituição de prêmio ou remuneração aos vencedores".
} 
interrompe processos de agudização das desigualdades sociais, com o intuito de viabilizar a criação de uma "sociedade de similares" (Castel, 1998, p. 34).

O direito administrativo público no Brasil, conclama o agente público como sendo "uma espécie dentro do gênero servidores estatais, são os que possuem com a administração relação de trabalho de natureza profissional e não eventual6" (Bandeira de Mello, 2016, p.248, [grifos nossos]). Assim, a flexibilização nas relações de trabalho ocorre, segundo Di Pietro (2016), em situações puramente excepcionais, a exemplo da ocorrência de catástrofes naturais, eventos esportivos pontuais entre outros, mas sempre coerentes ao interesse público.

O candidato à primeira eleição direta à presidência do Brasil, após um período ditatorial de 21 anos, elege como palavra de ordem de sua campanha a "caça aos marajás", um ataque explícito aos funcionários públicos que, para ele, recebiam altos salários e muitos direitos para pouco trabalho.

Collor de Mello (1990-1992), afeito aos princípios neoliberais e da Nova Gestão Pública, passa a difundir, com apoio midiático, a noção de um Estado oneroso e inábil para o enfrentamento dos novos desafios de uma sociedade em plena mutação e reconhece nas empresas privadas o lugar de excelência administrativa. O "caçador de marajás" envolve-se em inúmeros escândalos de corrupção e abandona o cargo, para evitar o processo de impeachment. Seu sucessor, Itamar Franco (1992-1995) a despeito de mais moderado, dá continuidade ao projeto neoliberal e aprova a Lei no 8.745, de 9 de dezembro de 1993 que ampliou o leque das formas de contração por excepcionalidade temporária de interesse público:

Art. $2^{\circ}$. Considera-se necessidade temporária de excepcional interesse público:

IV - Admissão de professor substituto e professor visitante; VII - admissão de professor, pesquisador e tecnólogo substitutos para suprir a falta de

\footnotetext{
${ }^{6}$ Dado o caráter de descentralização da política os estados da federação devem obedecer a Carta Magna e outras que regem, por exemplo, as formas de contratação, mas esses possuem autonomia para regular os planos de carreira, a caracterização do agente público, entre outros. Os agentes públicos que atuam no governo federal são regidos pela Lei no $8.112 / 90$ e, por exemplo, no estado de São Paulo pela lei n¹0.261/68.
} 
professor, pesquisador ou tecnólogo ocupante de cargo efetivo, decorrente de licença para exercer atividade empresarial relativa à inovação (Brasil, 1993, p. 1)

A recuperação histórica permite acompanhar a fertilização de um terreno para viabilizar a Reforma do Estado, iniciada no primeiro mandato do presidente Fernando Henrique Cardoso (1995-1998), o qual realiza a passagem do Estado Burocrático para o Gerencial. Nesse período são construídas as bases legais para o estabelecimento de parcerias público-privadas4, para a privatização das empresas estatais, como também para flexibilização das relações de trabalho no setor público. Apoiado nessa tríade o governo federal chancelou o mercado e o alçou a uma posição central na execução das políticas públicas.

O processo de redução da participação do Estado pela contratação de agentes públicos por outras vias que não as do concurso público, epiloga a cultura fordista - marcada pela forte presença de coletivos de trabalhadores nas fábricas, com condições e contratos de trabalhos homogêneos e labor duradouro - e colabora no esfacelamento dos coletivos, seguindo a tradição toyotista baseada na terceirização e na formalização de contratos por tempo determinado, todavia sendo praticado no interior do serviço público.

Todavia, o setor público, de certa forma, avança nos preceitos toyotistas concernentes à contratação e adota medidas impensáveis no setor privado: contratar trabalhadores sem a qualificação certificada para ocupação de um posto de trabalho central à garantia da qualidade e viabilidade do "negócio". Observa-se na seara normativa da educação brasileira, por meio da principal lei que organiza a educação no país, a Lei de Diretrizes e Bases da Educação Nacional (LDBEN) ${ }^{7}$ a permissão do estabelecimento de contratos de profissionais com notório saber e não necessariamente aqueles com formação específica para o exercício da docência. Dessa maneira, a flexibilidade ultrapassa as margens das formas de contrato e atinge diretamente o exercício da profissão.

${ }^{7}$ Brasil (1996). Lei no 9.394. Brasília: Câmara Federal. 
Verifica-se, de fato, uma orquestração que visa harmonizar um projeto de sociedade tomando a educação como um sustentáculo. Exemplifica-se a assertiva a partir da reforma do ensino médio ${ }^{8}$ centrada em dois aspectos: a carga horária anual deve passar, em cinco anos, de 800 para 1.400 horas, distribuídas em 200 dias letivos; o currículo sofre modificações e divide-se em duas partes: uma, comum; e, outra, de livre escolha do estudante conhecida como "itinerários formativos".

A lei, compreende-se, trilha caminhos tanto para a implementação do ensino a distância, posto que $44 \%$ dos alunos de 15 a 16 anos são trabalhadores (Organização para a Cooperação e Desenvolvimento Econômico [OCDE], 2018) e, portanto, de difícil cumprimento presencial da carga horária total; quanto para a concessão de espaço para o avanço das diversas formas de privatização na educação pública.

A parcela curricular optativa possibilita o estabelecimento de contratos descontínuos de docentes com empresas e, além disso, incorpora a lógica do notório saber, pois a não exigência de formação específica para exercício da profissão é disposta no art. 61, Inciso IV:

profissionais com notório saber reconhecido pelos respectivos sistemas de ensino, para ministrar conteúdos de áreas afins à sua formação ou experiência profissional, atestados por titulação específica ou prática de ensino em unidades educacionais da rede pública ou privada ou das corporações privadas em que tenham atuado (LDBEN, inciso IV, 1996).

Com base em Venco (2019) é possível afirmar que esse isso resultado de um processo que vem sendo aprimorado ao longo dos anos e liderado por alguns estados, a exemplo de São Paulo, uma vez que graduandos, profissionais com formação de nível superior desvinculadas da docência, como engenharia, direito, contabilidade entre outros, são contratados como professores temporários e ministram disciplinas afins, ou não.

Além desses aspectos, os marcos legais prosseguem sendo elaborados com a intenção de descomplexificar a participação do setor privado na educação,

\footnotetext{
${ }^{8}$ Brasil (2017). Lei no 13.415. Brasília: Câmara Federal.
} 
abarcando diversas iniciativas que não apenas as concernentes aos contratos de trabalho.

A lei 13.415/2017 dispõe no art. $36 \S 11$ [grifos nossos]: Para efeito de cumprimento das exigências curriculares do ensino médio, os sistemas de ensino poderão reconhecer competências e firmar convênios com instituições de educação a distância com notório reconhecimento, mediante as seguintes formas de comprovação (...)

Pondera-se, portanto, que a adoção de tais políticas desconsidera o sentido social da função pública como portadora e representativa do interesse geral da população e produz, com efeito, uma deformação do seu conceito.

As alas conservadoras emergentes no país desde o Golpe de Estado em 2016, promovem ataques constantes ao funcionalismo público ao requerer o fim da estabilidade àqueles que não apresentem produtividade e desempenho condizentes com metas estabelecidas (PLP9 550/2018; PLS ${ }^{10}$ 116/2017; PLP 248/1998), difunde junto aos eleitores uma visão de privilégios gozada pelos agentes públicos. Focaliza a performance individualizada e se opõe à busca pela efetividade do direito e da política social.

Estudo desenvolvido na França (Pors e Aschieri, 2015), sobre as características do trabalho realizado por agentes públicos, indica que opostamente ao pregado pelos apoiadores do Estado Mínimo, esse é qualificado como atípico em relação ao cumprido no setor privado.

Isso porque os servidores possuem: horários e dias anômalos ao conjunto da sociedade, a rotina é constantemente interrompida por outras urgências resultando na intensificação do trabalho, é comum terem descanso semanal inferior a 48 horas como parte dos assalariados do setor privado e, ainda, a realização de greves é, invariavelmente, julgada como ilegal, pois estão a serviço da população como na saúde e educação, entre outros.

\footnotetext{
${ }^{9}$ Projeto de lei do Senado Federal Complementar.

10 Projeto de lei de iniciativa do Senado Federal, na Câmara dos Deputados.
} 


\section{Rumo ao ocaso da função pública? A situação dos docentes no Brasil}

A pesquisa documental realizada com base nos dados estatísticos do Censo Escolar permite analisar as formas de contratação dos docentes em todo o País com maior acuidade. Como já explicitado, optou-se por reunir as formas atípicas de contratação, com vistas a vislumbrar o grau de precariedade objetiva, conceito forjado por Danièle Linhart (2014), a partir da elaboração de Castel (1998), relacionado a todo o tipo de contrato gerador de alguma forma de vulnerabilidade ao trabalhador.

Apreende-se que a norma prevalente de contratação, em todo o país, é ainda o concurso público. Contudo, chama a atenção o movimento acelerado de redução desse tipo de vínculo no período entre 2011 e 2018, em âmbito nacional, nas redes estaduais e com consequente elevação de formas mais precárias, como podem ser observadas no Gráfico 1.

Gráfico 1. Formas de contratação docente nas redes estaduais ${ }^{11}$ no Brasil: $2011-2018(\%)$

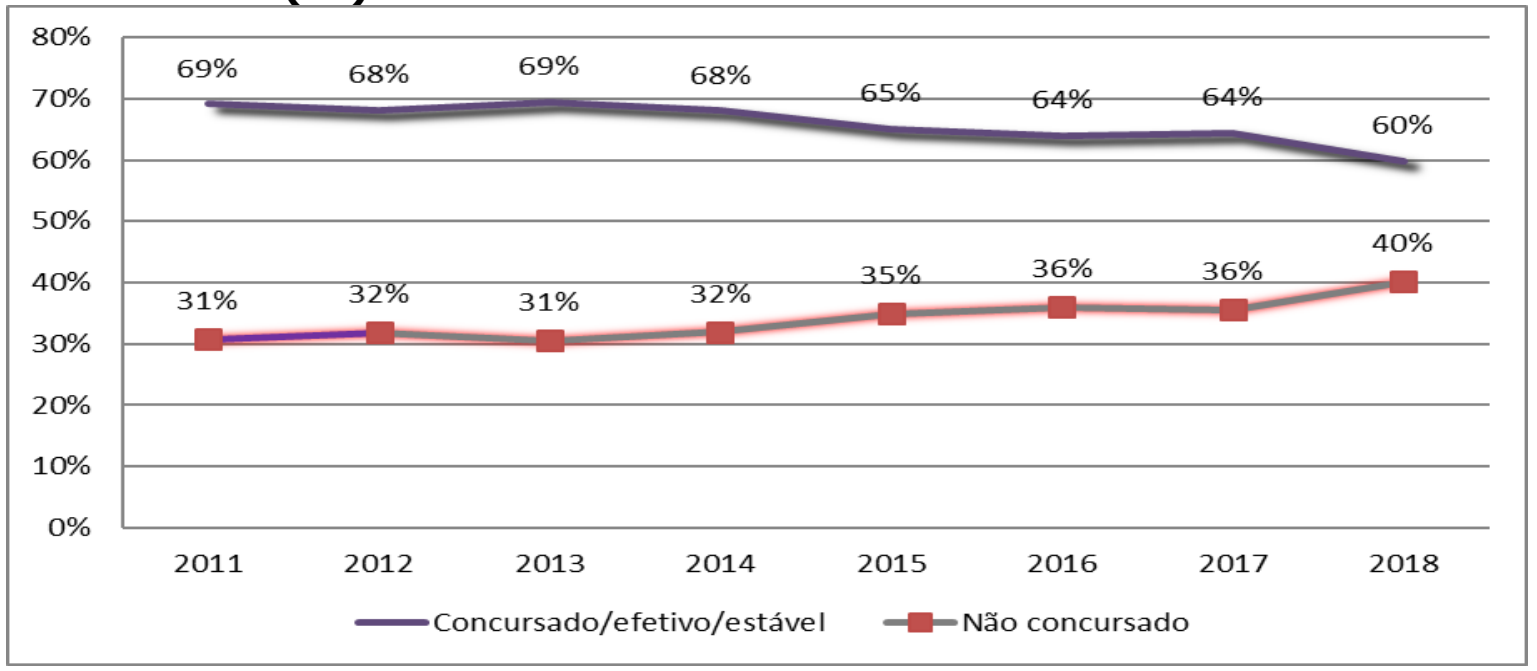

Fonte: MEC/Instituto Nacional de Estudos e Pesquisas Educacionais (INEP)/Censo Escolar, 2011 2018. Elaboração dos autores.

Dos vinte e seis estados e Distrito Federal apenas Amazonas, Rondônia, Rio Grande do Norte e Sergipe, conforme demonstrado no Gráfico 2, apresentaram

\footnotetext{
${ }^{11}$ Ver título IV da Lei de Diretrizes e Bases da Educação, n. 9.394 de 1996, que trata da organização da educação nacional.
} 
ascensão no número de docentes concursados. Todavia, é premente uma análise acurada da política educacional em cada um deles, acompanhada das oscilações nos números de matrícula e da pirâmide etária.

Destaca-se que os percentuais em si apontam para tendências que, necessariamente, demandam aprofundamento em exames específicos, pois aqui intenciona-se exclusivamente traçar o panorama da precariedade das relações de trabalho nas redes estaduais.

\section{Gráfico 2. Distribuição dos estados com contratação crescente, por concurso 2011-2018 (\%)}

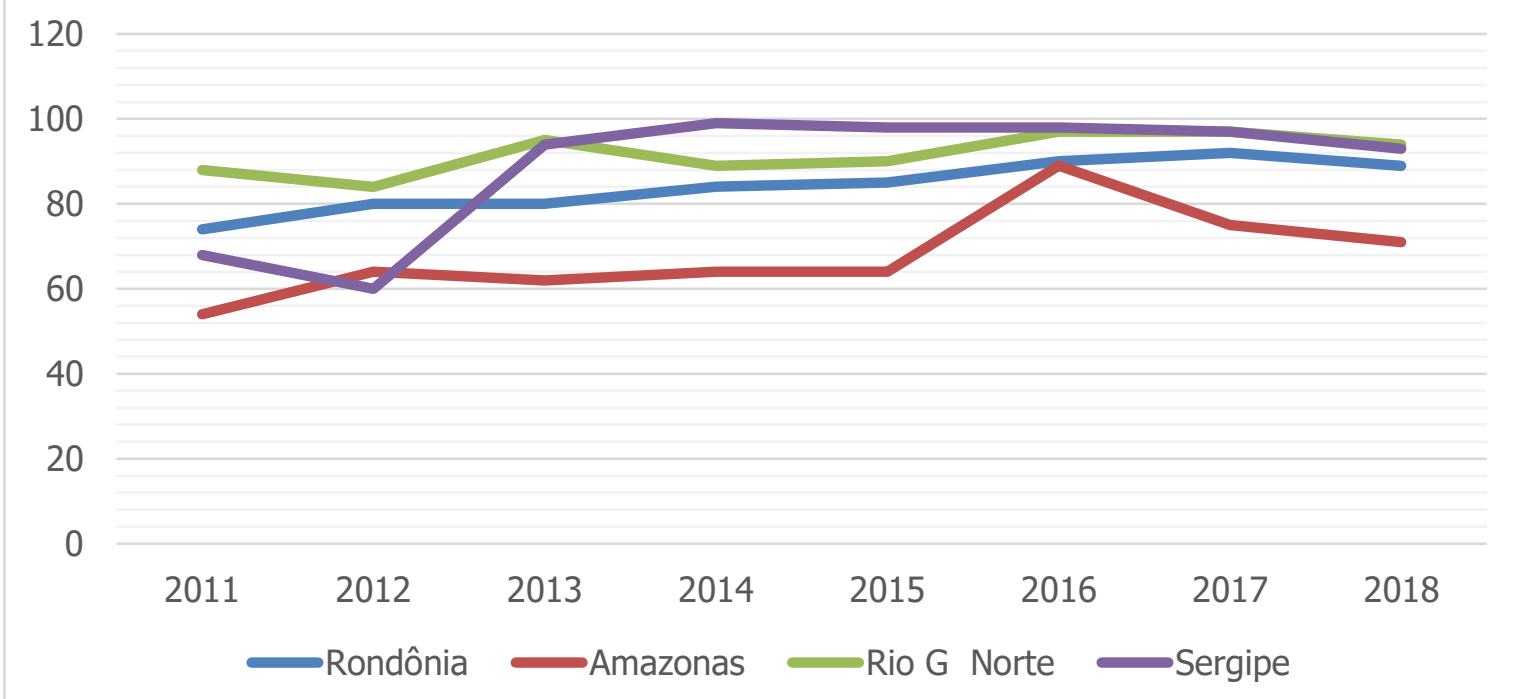

Fonte: MEC/INEP/Censo Escolar, 2011 - 2018. Elaboração dos autores.

Outros estados, por sua vez, mantiveram percentuais estáveis ou com ligeira alteração ao longo da série histórica no número de docentes concursados, conforme demonstrado no Gráfico 3.

Tal característica, contudo, não significa - exceto o estado do Rio de Janeiro - números ínfimos de contratação precária, a exemplo do Rio Grande do Sul cuja média no período é de praticamente 4 docentes precários em cada 10; ou Maranhão apresentando pouco mais de $1 / 3$ de contratos sem concurso público. 


\section{Gráfico 3. Distribuição dos estados com contratação estável e ou ligeiras variações, por concurso 2011-2018 (\%)}

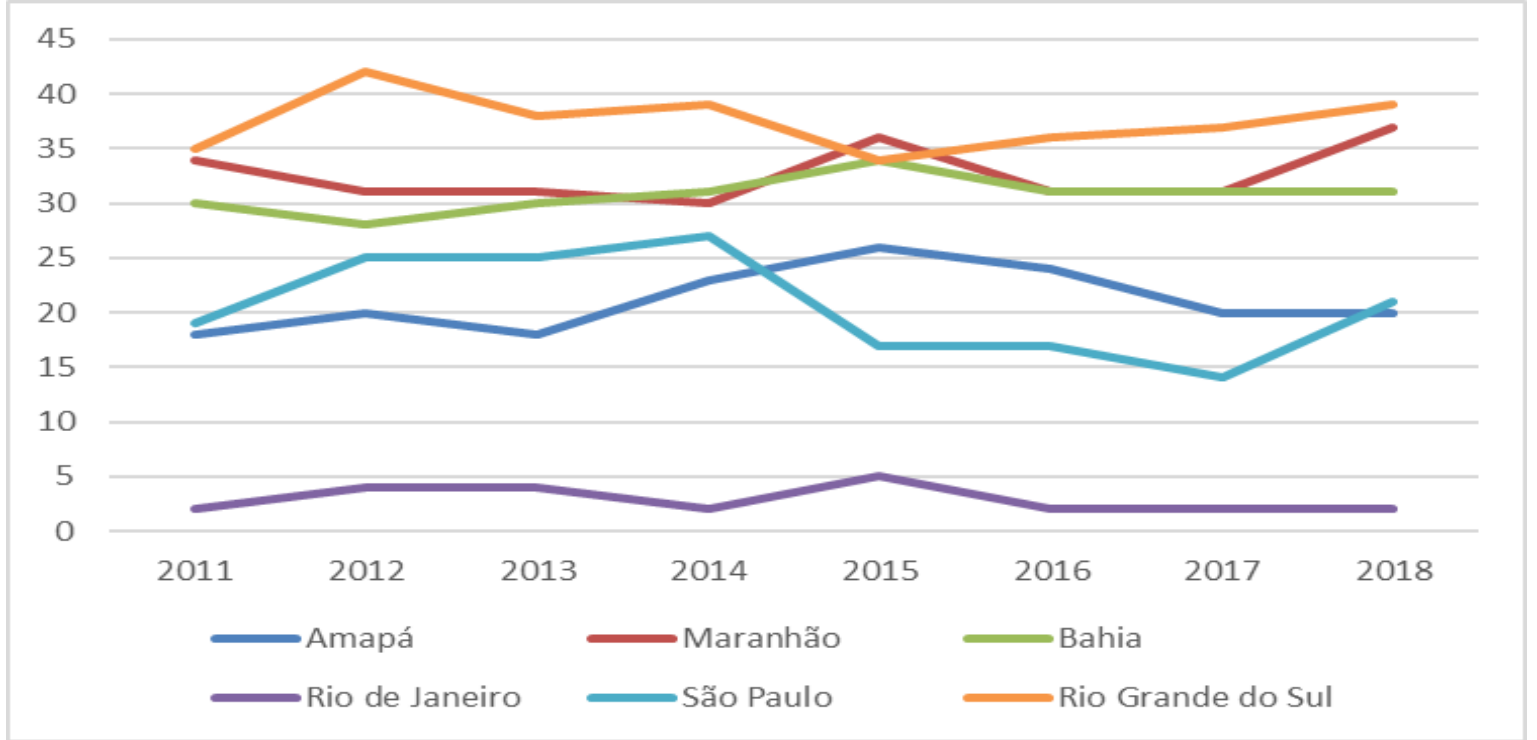

Fonte: MEC/INEP/Censo Escolar, 2011 - 2018. Elaboração dos autores

Convém, entretanto, problematizar a fidedignidade dos dados publicados pelo Ministério da Educação. Tomando como exemplo o estado de São Paulo, observam-se expressivas discrepâncias entre os fornecidos pelo Instituto Nacional de Estudos e Pesquisas Educacionais e os apresentados pelo governo paulista. A série histórica referente ao período de 1999 a 2019 informada pela Secretaria da Educação do Estado de São Paulo, indica que a precariedade objetiva é consideravelmente superior se comparada ao Educacenso, conforme Tabela 1.

Considerando o período coletado pelo censo educacional, 2011 a 2018, constata-se haver uma média de contratos precários da ordem de $21 \%$, enquanto pelos dados da própria Secretaria a média é pouco acima do dobro, $40 \%$ se tomado o mês de janeiro como base e 44\%, em novembro. Mesmo que haja diferenciações metodológicas entre as coletas, cabe indagar se ainda assim essas resultariam em divergências dessa monta. 
Tabela 1. Distribuição professores não efetivos, rede estadual paulista, SEE-SP* e INEP - 2011 a 2018 (em \%)

\begin{tabular}{|l|c|c|c|}
\hline & \multicolumn{2}{|c|}{ SEE-SP } & CENSO/INEP \\
\hline 2011 & Janeiro & Novembro & 19 \\
\hline 2012 & 47 & 48 & 25 \\
\hline 2013 & 40 & 49 & 25 \\
\hline 2014 & 45 & 52 & 27 \\
\hline 2015 & 39 & 45 & 17 \\
\hline 2016 & 39 & 42 & 17 \\
\hline 2017 & 41 & 40 & 21 \\
\hline 2018 & 38 & 40 & 21 \\
\hline MÉDIA & 29 & 44 & 14 \\
\hline
\end{tabular}

Fonte: SEE-SP, INEP, 2011-2018. Elaboração própria

*Alterada a sigla da Secretaria da Educação de SEE-SP para SEDUC, cf Resolução SE 18/2019.Optouse pela anterior em razão do texto se referir a período anterior à mudança.

Assim, apreende-se que o estado de São Paulo vem recrudescendo a participação de contratos, contudo destaque-se ser tal medida amparada em outras formas de racionalização econômica, a exemplo do fechamento de salas, ampliação do número de alunos por turma, possibilidade de concursados ampliarem a jornada de trabalho em até 64 horas semanais, entre outras.

\section{Os destaques nacionais da precariedade}

$\mathrm{Se}$, conforme ressaltado, a precariedade nas relações de trabalho praticada pelos governos estaduais entre professores cresce no país, é relevante especificar em quais estados a educação está sendo efetivada por docentes não concursados que, além de terem vínculos instáveis, também se desconhece a formação e a qualidade dessa dos profissionais envolvidos.

É importante registrar a não intencionalidade, na presente análise, em atacar as e os docentes, posto que se reconhece sua importância na concretização do direito à educação, mas, sim sobrelevar a responsabilidade dos governos na oferta de condições dignas e estáveis a esse segmento cuja atuação é formar gerações. 
A média de contratos de professores não efetivos é, na série histórica, de $40 \%$. Assim, considerou-se na Tabela 2 os estados que lograram percentual igual ou superior a ela e constata-se que 15 deles encontram-se nessa situação.

Se, de um lado, no período compreendido entre 2011 e 2018 cinco deles apresentaram média igual ou superior a $61 \%$, por outro, a evolução ao longo dos anos é o dado que mais chama a atenção. Sobre isso é possível afirmar que praticamente 8 em cada 10 professores das redes estaduais no Acre e Espírito Santo não são concursados em 2018; outros estados, igualmente alçam percentuais próximos a essa marca como Tocantins, Santa Catarina, Minas Gerais e, portanto, a relação que poderia se estabelecer entre maior adesão a contratos flexíveis em estados com arrecadação reduzida ${ }^{12}$ e talvez não se sustentaria mesmo com a Lei de Responsabilidade Fiscal.

Tabela 2. Distribuição de professoras/es não efetivos, redes estaduais, 2011 a 2018 (\%)

\begin{tabular}{|l|cccccccc|}
\hline \multicolumn{1}{|c}{2011} & 2012 & 2013 & 2014 & 2015 & 2016 & 2017 & 2018 \\
\hline ACRE & 54 & 63 & 65 & 58 & 62 & 78 & 72 & 78 \\
AMAPÁ & 18 & 20 & 18 & 23 & 26 & 24 & 20 & 20 \\
AMAZONAS & 46 & 44 & 38 & 36 & 38 & 21 & 25 & 29 \\
BAHIA & 30 & 28 & 30 & 31 & 34 & 31 & 31 & 31 \\
CEARÁ & 60 & 63 & 69 & 72 & 61 & 57 & 60 & 61 \\
D. FEDERAL & 26 & 29 & 28 & 28 & 25 & 26 & 34 & 40 \\
ESP. SANTO & 60 & 68 & 71 & 74 & 73 & 46 & 59 & 66 \\
GOIÁS & 2 & 20 & 38 & 35 & 36 & 42 & 44 & 50 \\
M. GROSSO & 68 & 65 & 64 & 66 & 37 & 62 & 65 & 64 \\
MARANHÃO & 34 & 31 & 31 & 30 & 36 & 31 & 31 & 37 \\
MATO G SUL & 58 & 59 & 61 & 61 & 61 & 62 & 65 & 71 \\
M. GERAIS & 28 & 20 & 12 & 19 & 57 & 65 & 65 & 68 \\
PARÁ & 14 & 17 & 17 & 12 & 14 & 12 & 20 & 30 \\
PARAÍBA & 55 & 52 & 44 & 47 & 29 & 30 & 28 & 52 \\
PARANÁ & 37 & 37 & 39 & 42 & 31 & 39 & 32 & 35 \\
PERNAMBUCO & 37 & 41 & 44 & 47 & 49 & 52 & 45 & 48 \\
PIAUÍ & 46 & 43 & 39 & 15 & 63 & 55 & 44 & 43 \\
RIO G. DO SUL & 35 & 42 & 38 & 39 & 34 & 36 & 37 & 39 \\
RIO DE JANEIRO & 2 & 4 & 4 & 2 & 5 & 2 & 2 & 2 \\
R GDE NORTE & 22 & 16 & 5 & 11 & 10 & 3 & 3 & 6 \\
RONDÔNIA & 26 & 20 & 20 & 16 & 15 & 10 & 8 & 11 \\
RORAIMA & 16 & 31 & 41 & 45 & 48 & 54 & 43 & 48 \\
S CATARINA & 50 & 59 & 56 & 53 & 53 & 56 & 60 & 63 \\
SÃO PAULO & 19 & 25 & 25 & 27 & 17 & 17 & 14 & 21 \\
SERGIPE & 32 & 40 & 6 & 1 & 2 & 2 & 3 & 7 \\
TOCANTINS & 44 & 31 & 37 & 38 & 44 & 51 & 60 & 69 \\
\hline
\end{tabular}

Fonte: MEC/INEP/Censo Escolar, 2011 - 2018. Elaboração dos autores.

12 De acordo com dados da Receita Federal do Brasil (2020). Recuperados de https://receita.economia.gov.br 
Dados os limites de um artigo, destacam-se aqui dois deles: os estados de Minas Gerais e São Paulo, pioneiros na adesão aos princípios da Nova Gestão Pública implementada pelo governo federal. Minas Gerais contava com 66.073 docentes concursados em 2011, número reduzido à metade no período de quatro anos e representa uma diminuição de $60 \%$ dos contratos estáveis. Tal fato pode ser explicado, ao menos em parte, pela aprovação de uma Lei (100/2007) que remonta os anos 1930 do país, a qual visava regularizar a situação trabalhista de 98 mil docentes em situação de alta precariedade nas relações de trabalho, pois não contavam sequer com os direitos previstos na CLT.

A partir deste expediente o governo de Minas Gerais efetivou, sem concurso público, esse conjunto de professores. No entanto, sete anos após o Supremo Tribunal Federal considerou a medida inconstitucional, ficando a outro governador a incumbência de demiti-los. Amorim et al (2018) indicam, a partir do uso de base de dados distinta da empregada por nós, que o governo mineiro classificava os contratos de docentes em três diferentes tipos: efetivos (concursados), designados (temporários) e efetivados (Lei n. 100).

Possivelmente, como medida para contornar a gravidade do problema, observa-se a nítida elevação dos contratos temporários, pois passam de 25.816 professores temporários em 2011 para 61.654 em 2018, ou seja, um acréscimo de 139\% em relação a 2011.

Já em São Paulo, as formas flexíveis de contratação se mantiveram em um movimento de estabilidade, em termos percentuais por ano. Entretanto, os números absolutos revelam que 30.346 docentes atuam para além da função pública e com relações de trabalho precárias, sem garantias.

Para Venco (2020), há um processo de quasi-uberização promovido pelo governo paulista, pois, assim como os motoristas da empresa Uber, é comum ter professores não efetivos, sem formação específica para a docência e, ainda, com aulas a eles atribuídas para disciplinas díspares de sua formação. Na mesma linha comparativa, os docentes são levados a ampliar suas horas de trabalho para a obtenção de um ganho mensal para subsistência. 
É importante refletir que o professor nessa condição assume as responsabilidades inerentes à função pública, sem, contudo, ser reconhecido juridicamente como tal, nem tampouco detentor de direitos análogos aos dos servidores públicos.

Ademais, a possibilidade da contratação legal de caráter temporário amparase na excepcionalidade e na provisoriedade. Mas, de fato, constata-se a habitualidade e a permanência de contratos com restrição de direitos trabalhistas, rebaixamento do valor da remuneração com a desvalorização e a desqualificação do trabalho, além de outras questões (Gomes, 2017).

\section{O sexo e a cor da precariedade objetiva}

Dados oficiais do Instituto Brasileiro de Geografia Estatística (IBGE) registraram no último Censo Demográfico (2010) cerca de quatro milhões de mulheres a mais do que homens no total da população brasileira.

Para além das distinções biológicas entre os sexos, o gênero se fundamenta em dois aspectos, quais sejam:

se exerce materialmente em dois campos fundamentais: 1) a divisão sociosexuada do trabalho e dos meios de produção; e, 2) a organização social do trabalho de procriação ou as capacidades reprodutivas das mulheres são transformadas e frequentemente exacerbadas por diversas intervenções sociais (Mathieu, 2000, p.192, tradução livre)

$E$ essas interferem nas estruturas do mercado de trabalho, e, confere às mulheres profissões e ocupações vinculadas aos cuidados e atributos femininos. Louise Howe (1977), a partir das mesmas percepções cunhou o termo "colarinhos cor-de-rosa" - amplamente adotado nos estudos sobre o trabalho feminino -, por indicar postos de trabalho majoritariamente femininos e marcados pela baixa remuneração e desvalorização social, como professoras, enfermeiras, operadoras de telemarketing entre outras (Venco, 2009).

A docência é eminentemente feminina, assegurada por documento do Banco Mundial: cerca de 75\% dos professores da América Latina são mulheres; pelo Inep 
(Educacenso) cujos dados indicam que, no Brasil, pouco mais de 8 em cada 10 professores são do sexo feminino em todas dependências administrativas.

Em outras palavras, a despeito da prevalência feminina na docência, sua participação nas redes estaduais em todo o Brasil apresentou movimento negativo na ordem de $12,5 \%$, contra ligeira participação masculina (3,8\%) entre os anos de 2012 e 2018, como demonstrado no Gráfico 4.

\section{Gráfico 4. Distribuição total dos docentes, segundo sexo ( $n^{\circ}$ abs) - redes estaduais}

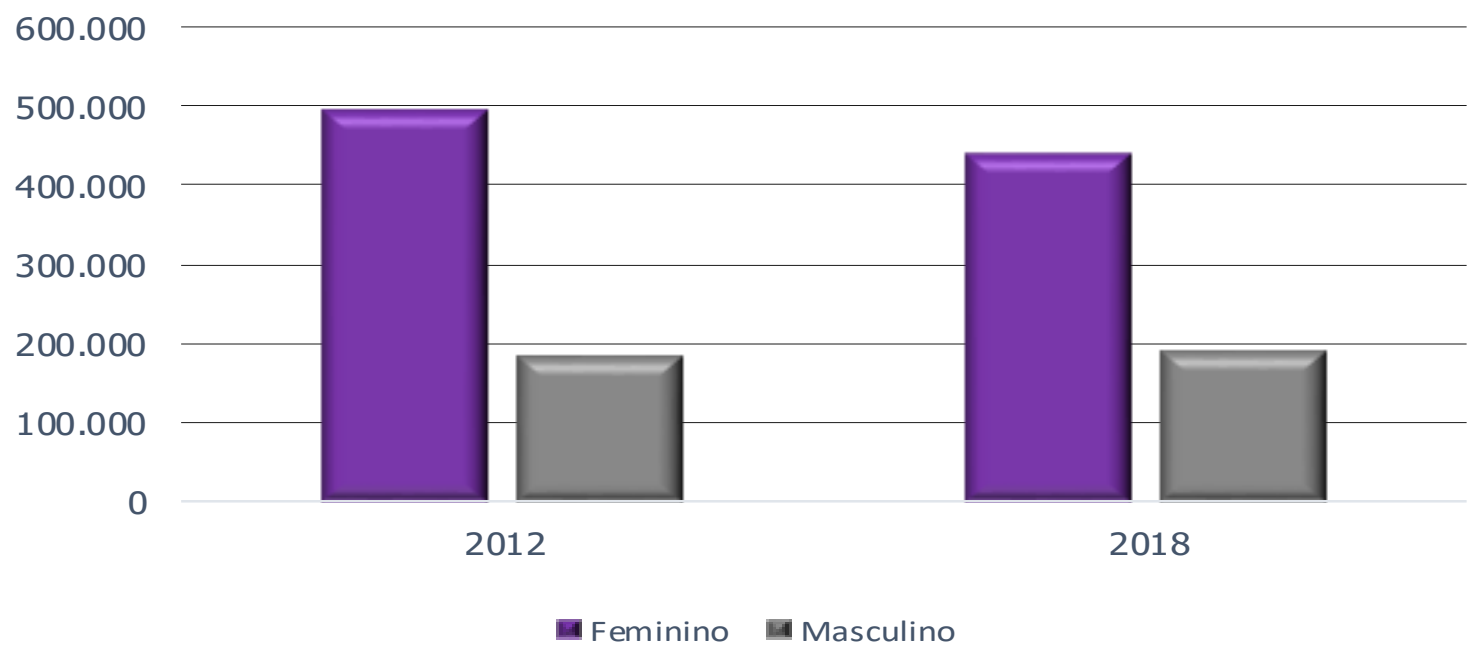

Fonte: MEC/INEP/Censo Escolar, 2012,2018. Elaboração dos autores.

A análise da distribuição entre os sexos dos não concursados, disposta na Tabela 3, indica que em 2012 pouco mais de 1/3 das mulheres encontravam-se nesse tipo de contrato em todo o Brasil, eram 31\% contra 34\% de homens. Entretanto, seis anos após, em 2018, o número de mulheres não concursadas teve ampliação de dez pontos percentuais, enquanto entre os homens apenas quatro pontos. Reafirmando, portanto, de um lado, a prevalência das mulheres na profissão e, de outro, vivenciarem proporcionalmente e em maior número, a precariedade objetiva ao longo da série histórica. 
Tabela 3. Distribuição de docentes, segundo formas de contratação pelas redes estaduais no Brasil, e sexo: 2012 e 2018 (\%)

\begin{tabular}{|l|c|c|c|c|}
\hline & \multicolumn{2}{|c|}{2012} & \multicolumn{2}{c|}{2018} \\
\hline & Feminino & Masculino & Feminino & Masculino \\
\hline CONCURSADOS & 69 & 66 & 59 & 62 \\
\hline NÃO CONCURS. & 31 & 34 & 41 & 38 \\
\hline TOTAL & 100 & 100 & 100 & 100 \\
\hline
\end{tabular}

Fonte: MEC/INEP/Censo Escolar, 2012,2018. Elaboração dos autores.

Se a precariedade entre docentes é feminina, cabe indagar se esse segmento se vincula aos negros e pardos, historicamente ocupantes de postos de trabalho mais desvalorizados e com salários mais baixos (Teixeira, 2013).

De acordo com o censo demográfico (IBGE, 2010) a população brasileira é de pouco mais de 190 milhões de habitantes e, desse total, $51 \%$ são pretos ou pardos, respeitando-se aqui a denominação adotada pelo governo federal. Não obstante, entre os docentes a mesma proporção não se concretiza e indica ser a docência uma profissão constituída predominantemente por pessoas brancas, porém com número expressivo de não respondentes.

Tabela 4. Distribuição dos docentes, segundo raça/cor - redes estaduais, 2012 e 2018

\begin{tabular}{|c|c|c|c|c|c|c|}
\hline & & Branca & $\begin{array}{c}\text { Preta/ } \\
\text { Parda }\end{array}$ & Amarela & Indígena & ND* \\
\hline Concursados & 2012 & 235.190 & $\mathbf{1 1 0 . 5 4 4}$ & 4.268 & 1.132 & 122.338 \\
\hline & 2018 & 191.781 & $\mathbf{9 6 . 2 9 6}$ & 3.235 & 1.189 & 92.649 \\
\hline Não concursados & 2012 & 100.813 & $\mathbf{5 7 . 3 3 0}$ & 1.019 & 4.559 & 53.578 \\
\hline & 2018 & 110.466 & $\mathbf{8 3 . 9 8 8}$ & 1.109 & 6.580 & 142.973 \\
\hline
\end{tabular}

Fonte: MEC/INEP/Censo Escolar, 2012,2018. Elaboração própria

* Não declarado

Com base na Tabela 4 observa-se que há concentração de pessoas pretas/pardas nos contratos precários e aumento pouco representativo entre os 
concursados, três pontos percentuais; no conjunto de não concursados o percentual passou de 35\%, em 2012, para 42\% em 2018.

Guimarães (1999) constrói uma reflexão acerca da construção social do termo raça no Brasil e seus desdobramentos nas formas de subordinação da população preta e parda. Com base em Marx e Engels (2007, p. 94) é possível afirmar que "não é a consciência que determina a vida, é a vida que determina a consciência" e, portanto, a história da humanidade tece valores nas interações e cria sentidos subjetivos para ações objetivas. Assim, defende-se haver, na formação da sociedade brasileira a edificação da inferioridade dos afrodescendentes em vários aspectos:

O racismo origina-se da elaboração e da expansão de uma doutrina que justificava a desigualdade entre os seres humanos (seja em situação de cativeiro ou de conquista) não pela força ou pelo poder dos conquistadores (uma justificativa política que acompanhara todas as conquistas anteriores), mas pela desigualdade imanente entre as raças humanas (a inferioridade intelectual, moral, cultural e psíquica dos conquistados ou escravizados) (Guimarães, 1999, p. 104).

Os dados do censo educacional indicam concentração de pretos e pardos, nos contratos precários e confirmam, portanto, a análise do autor. E, o número relevante de não respondentes pode estar associado tanto à ausência do dado nas escolas quanto à desvalorização do preenchimento sobre ele quando informado ao Ministério da Educação. É importante destacar a presença da ideologia do branqueamento no Brasil que, segundo Domingues (2002, p.565) é compreendida como a introjeção "dos modelos culturais brancos pelo segmento negro, implicando a perda do seu ethos de matriz africana" e, assim, pode levar à autodeclaração distinta da realidade.

Desse conjunto de característica pessoais sobre sexo e cor dos docentes não efetivos, constata-se direta e indiretamente a opção política adotada pelo poder público em relação à docência na educação básica pública, cujo piso nacional é de aproximadamente US\$532,00 (2020). Já nos Institutos Federais, os salários oscilam 
entre US\$1650,00 a US\$ 3200 e, nesses, 73 \% dos docentes são homens (Oliveira, et al, 2017)

A grande concentração feminina é historicamente indicativa de profissões que vivenciam condições de trabalho mais degradadas e desgastantes física e mentalmente ${ }^{13}$, baixos salários e desvalorização social, como mencionado anteriormente.

Soma-se a este cenário o fato de haver uma quantidade expressiva de docentes exercendo a profissão sem a devida formação. Os dados indicam que uma versão prévia do possível "notório saber" sustentada pela Lei n. 13.415/2017 já estava, de certa forma, em curso informalmente há algum tempo, pois, estudos realizados por Venco (2019) sobre o governo do estado de São Paulo apresentam formas flexíveis de contratação mais precisas desde 1968. Em 1989, o estado possibilitou o ingresso de graduandos para exercer a docência, desde que fossem cursistas do ano final.

Dez anos depois, em pleno exercício da lógica da Nova Gestão Pública, outra medida legal amplia essa perspectiva e passa a admitir estudantes com apenas um semestre cursado e com a possibilidade de ministrar aulas diversas à formação em curso.

Soma-se a essa iniciativa outra que agrava ainda mais a situação da educação: os temporários no estado de São Paulo ministram aulas díspares à formação que, entretanto, ainda está em curso para parcela dos temporários.

Nesse contexto, há, no estado de São Paulo, dez diferentes categorias para contratos dos professores. Além dos concursados, outras duas obtiveram estabilidade após a promulgação da Constituição Federal, em 1988, uma vez que conferiu tal direito aos servidores em exercício há mais de cinco anos. As demais são de caráter temporário e eventual, sob regime da referida CLT, ou seja, tendo condições iguais aos trabalhadores do setor privado.

\footnotetext{
13 Sobre isso ver: Bruschini, C., e Lombardi, M.R (2002). Instruídas e trabalhadeiras: trabalho feminino no final do século XX. Cadernos Pagu, [S.I.], v.17-18, p.157-196. doi: 10.1590/S010483332002000100007 . Hirata, H.S (2000). Divisão sexual do trabalho: novas tendências e problemas atuais. In FUNDAÇÃO SEADE. Gênero no mundo do trabalho. São Paulo: Ellus.
} 


\section{Conclusões}

Visou-se debater no presente artigo, se estaria a função pública, no que concerne às relações de trabalho entre docentes nas escolas estaduais brasileiras, em vias de arrefecimento progressivo. Se o fim da função pública é uma distopia ou efetivamente uma realidade vivenciada há décadas por professoras e professores brasileiros.

Procurou-se demonstrar que os estados adotam estratégias para contornar o não provimento dos cargos para professores com medidas paliativas que, podese afirmar, por ora, tratar-se de uma situação que perpassa da provisoriedade para outra permanente e definitiva.

Os dados apresentados revelam a adoção crescente de medidas racionalizadoras, inspiradas na lógica empresarial, na concretização do direito à educação. Outras, ainda em fase de coleta na presente pesquisa, indicam a existência de formas de contratação de docentes mais escusas, pois são realizadas via programas contratados pelos órgãos públicos e executados por Fundações, Organizações-não-governamentais e outras entidades privadas e, portanto, os números podem ser ainda mais surpreendentes em relação ao definhamento da função pública na educação, acompanhada de profunda distorção se feita pela iniciativa privada.

O Brasil conta com Lei específica, n. 13.005/2014, que dispõe sobre o Plano Nacional de Educação (PNE) para execução em dez anos. Esse é composto por objetivos e metas e cada estado realiza seu próprio planejamento, por ele orientado.

A meta 18 do PNE pontua que se deve assegurar no prazo de 2 (dois) anos a existência de planos de Carreira aos profissionais da educação básica e superior públicas de todos os sistemas de ensino, de maneira que as escolas públicas tenham, ao menos, $90 \%$ de postos de trabalho efetivos.

Como visto, os dados do censo escolar de 2018 atestam que tal meta está distante de ser concretizada e pode conferir novo impulso às formas de privatização, pois os governos estaduais apoiados nas reformas em curso, a exemplo da realizada no ensino médio, poderão firmar contratos com empresas, fundações entre outras, 
com vistas a cumprir a meta até 2024, ano final de execução do Plano Nacional de Educação.

É válido igualmente argumentar para além das formas de contratação o sentido do coletivo na profissão. A fragmentação dos docentes ocorre por diversas vias: por se tratar de uma política educacional descentralizada, ou seja, estados e municípios são autônomos para criarem seus planos de cargos e salários, contanto que respeitem o piso nacional do professor.

Se houvesse uma carreira única para todo o Brasil, a exemplo do que ocorre nas Universidades e ou Institutos Federais, o poder de organização e negociação pela valorização profissional poderia ocorrer em outras bases; e, por tipo de contrato, pois além de serem vinculados ao estado, ao município e, em menor número, ao governo federal, um professor concursado, conforme estudo realizado não adere à pauta de reivindicações dos temporários e vice-versa. De um lado, os professores efetivos vinculados à rede do estado de São Paulo consideram inadmissível a não reposição de docentes concursados (Venco, 2019).

Este aspecto, para eles, oferece maiores garantias para realização do trabalho coletivo, posto que se ampliam, mesmo que hipoteticamente, as possibilidades de permanência na mesma escola. Do lado dos temporários no estado de São Paulo, por exemplo, a rivalidade entre os que mantem relações de trabalho distintas está colocada no cotidiano da escola. $O$ relato comum observado consistia na assertiva que os "Eles [os concursados] são muito reclamões... só ficam pedindo mais e mais. Eles não querem dar aula, nós, sim, nós temos energia e somos pau pra toda obra" (Venco, 2019 p. 13).

Os dados que se apresentam podem apenas sinalizar o movimento realizado pelos organismos e agências multilaterais, no sentido de abrir espaço para se apropriar do fundo público da educação. Torna-se salutar o destaque feito por ao mencionar que no contexto atual do capitalismo, a formação da taxa de lucro do capital perpassa pelo fundo público.

Os organismos multilaterais podem ser ordenados no grupo de entidades que fazem parte do processo de financeirização da economia, cuja educação se apresenta como um relevante espaço de ocupação. Com este processo, os 
mercados financeiros, de onde são representantes, passam a disputar cada vez mais recursos que, pressionados, funcionam como um elemento fundamental para a reprodução do capital e também para a força de trabalho

Nesse caso, sinaliza-se para o cenário de disputa de projeto de sociedade, no qual o campo progressista tenta garantir o uso da verba pública para as necessidades das políticas educacionais; quando em outro momento, as variadas representações do capital buscam, com a força hegemônica, assegurar a participação do Estado na reprodução de políticas de subsídios econômicos, cujo fundo público da educação tem sido um lócus a ser explorado por recentes e incisivas investidas.

Entretanto, recentes movimentos tentam de alguma forma escamotear esta pretensa aura de estabilidade ao propalar-se no debate sobre a manutenção do Fundo de Desenvolvimento da Educação Básica e de Valorização dos Profissionais da Educação (FUNDEB), e da proposta do governo de Jair Messias Bolsonaro sobre a desvinculação dos recursos da receita resultante líquida de impostos para a Manutenção e Desenvolvimento do Ensino (MDE), prevista na Constituição Federal de 1988 em seu artigo 211, cujo pano de fundo é o interesse sobre o fundo público da educação.

Com o sinal declarado de que esfacelar carreiras de Estado é colocar em risco a função pública do ensino, atenta-se para as ponderações construídas tendo por base Castel (1998), na qual nos remete à relevância da preservação de servidores públicos, dado que o trabalho por eles realizado se vincula diretamente à garantia dos direitos da população à educação. Desta forma, apreende-se, e o contexto histórico demonstra, que se adota no Brasil de forma progressiva alguns percalços e instrumentos da Nova Gestão Pública, especialmente no que se refere à forma flexível do trabalho.

Face a tal composição contextual, problematiza-se a partir de uma sintomática contradição: como a política educacional no Brasil pretende atingir níveis de excelência, se em tese, não prioriza a permanência de docentes e, sobretudo com remuneração atrativa e justa? 
Ou, nas palavras do antropólogo Darcy Ribeiro: "a crise da educação no Brasil não é uma crise, é um projeto".

\section{Referências bibliográficas}

Banderia de Mello, C. A (2010). Curso de direito administrativo. São Paulo: Malheiros Editores.

Bresser-Pereira, L.C. (1995). A reforma gerencial do Estado de 1995. Revista de Administração Pública. Disponível em https://bit.ly/3cDFiRD

Brasil (1924). Constituição Política do Império do Brazil. Brasília: Senado Federal. Brasil (1891). Constituição da República dos Estados Unidos do Brasil. Brasília: Senado Federal.

Brasil (1934). Constituição da República dos Estados Unidos do Brasil. Brasília: Senado Federal.

Brasil (1946). Constituição dos Estados Unidos do Brasil. Brasília: Senado Federal. Brasil (1988). Constituição da República Federativa do Brasil. Brasília: Senado Federal.

Brasil (2017). Lei n. 13.415, de 16 de fevereiro. Brasília: Câmara Federal.

Brasil (20140. Lei n. 13.005, de 25 de junho. Brasília: Câmara Federal. Brasil (2007). Lei n. 11.494, de 20 de junho. Brasília: Câmara Federal Brasil (1996). Lei n. 9.394, de 20 de dezembro. Brasília: Câmara Federal. Brasil (1993). Lei n. 8.745, de 9 de dezembro. Brasília: Câmara Federal. Brasil (1993). Lei n. 8.666, de 21 de junho. Brasília: Câmara Federal. Brasil (1990). Lei n. 8.112, de 11 de dezembro. Brasília: Câmara Federal. Brasil (1968). Lei n. 10.261, de 28 de outubro de 1968. São Paulo. Assembléia Legislativa Estadual.

Brasil (1943). Lei n. 5.452, de 10 de maio. Brasília: Câmara Federal.

Castel R. (1998). As metamorfoses da questão social: uma crônica do salário. Petrópolis, RJ: Vozes.

Carvalho, J. M. de. (1997). Mandonismo, Coronelismo, Clientelismo: Uma Discussão Conceitual. Revista Dados. doi: 10.1590/S0011-52581997000200003. 
Di Pietro, M. S. Z. Direito Administrativo. (2016). Rio de Janeiro: Forense.

Domingues, P. J. (2002). Negros de almas brancas? A ideologia do branqueamento no interior da comunidade negra em São Paulo, 1915-1930. Estudos AfroAsiáticos, 24 (3), 563-600.

Engels, F. (1984). A origem da família, da propriedade privada e do Estado. São Paulo: Boitempo.

Guimarães, A. S. (1999). Combatendo o racismo: Brasil, África do Sul e Estados Unidos. Revista Brasileira de Ciêncis Sociais, 14 (39), 103-115.

Gomes, T. (2017). Contratação de professores temporários nas redes estaduais de ensino no Brasil: implicações para a categoria docente. Disponível em https://ppge.educacao.ufrj.br/ppge.html

Holanda, S. B. de (1969). Raízes do Brasil. Rio de Janeiro: Livraria José Olympio.

Howe, L. K. (1977) Pink collars workers: inside the world of women's work. New York: Putnam.

Instituto Brasileiro de Geografia Estatística. (2010). Censo Demográfico. Brasília.

Linhart, D. (2014). Modernização e precarização da vida no trabalho. In Antunes, R. (Org.), Riqueza e Miséria do Trabalho. São Paulo: Boitempo.

Marx, K. e Engels, F. (2007). A ideologia alemã. São Paulo: Boitempo.

Mathieu, N. C. (2000). Sexe et genre. In H. Hirata, F. Laborie, H. Le Doaré, H. e D. Senotier (Orgs.), Dictionnaire critique du féminisme. Paris: PUF.

Organização para a Cooperação e Desenvolvimento Econômico. (2018). Programa Internacional de Avaliação de Estudantes. Disponível em https://bit.ly/3icLNMj

Oliveira, F. (1998). Os direitos do antivalor: a economia política da hegemonia imperfeita. Petrópolis-RJ: Vozes.

Oliveira, R de S., Sales, M. A. e Silva, L. G. da (2017). Professor por acaso? A docência nos Institutos Federais. Revista Profissão Docente, 17 (37), 5-16. doi: https://doi.org/10.31496/rpd.v17i37.1115.

Pors, A. e Aschieri, G. (2015). La fonction publique du XXI Siècle. Ivry-sur-Seine: Les éditions de l'atelier. 
Rocha, F. R. F. e Macário, E. (2016). O impacto da EC 95/2016 e da PEC 287/2016 para a Previdência Social Brasileira. SER Social, 18 (39), 444-460. doi: 10.26512/ser_social.v18i39.14632.

Teixeira, M. O. (2013). O mercado de trabalho reitera relações desiguais que se constroem no âmbito das relações econômicas e sociais. In Fundação Perseu Abramo e Fundação Friedrich Ebert (Org.), Classes? Que classes? Ciclo de debates sobre classes sociais. 1a. ed. São Paulo: Editora Fundação Perseu Abramo.

Weber, M. (1999) Economia e Sociedade. Brasília: Editora UnB.

Venco, S. (2019). Uberização do trabalho: um fenômeno de tipo novo entre os docentes de São Paulo, Brasil? Cadernos de Saúde Pública. doi: 10.1590/0102$311 \times 00207317$.

Venco, S. (2009). Centrais de teleatividades: o surgimento dos colarinhos furtacores. In R. Antunes e R. Braga, Infoproletários: degradação real do trabalho virtual. São Paulo: Boitempo Editorial.

Venco, S. (2020). Há um processo de quasi-uberização dos docentes. Adquirida a partir da página Contrapoder. Disponível em https://bit.ly/3n10Lsw

Recebido em: 16 de julho de 2020 Aceito em: 28 de setembro de 2020

\section{(i) (8)}

Revista Educación, Política y Sociedad (ISSN 2445-4109) está distribuida bajo una Licencia Creative Commons Atribución-NoComercial 4.0 Internacional 